\title{
LA RESPONSABILIDAD SOCIAL EMPRESARIAL: APORTES DEL PADRE ALBERTO HURTADO EN CHILE
}

\author{
Corporate Social Responsibility: Contributions \\ of Father Alberto Hurtado in Chile
}

\author{
Jaime Caiceo Escudero \\ jcaiceo@hotmail.com \\ Universidad de Santiago de Chile. Chile
}

Fecha de recepción: 09/01/2019

Fecha de aceptación: 26/02/2019

RESUMEN: Desde mediados del siglo pasado se comenzó a acuñar el concepto de Responsabilidad Social Empresarial-RSE-, el cual paulatinamente se ha ido precisando e introduciendo en él las nuevas necesidades y problemas de la cambiante sociedad actual.

Sin embargo, en 1947 el P. Alberto Hurtado fundó la Asociación Sindical Chilena -ASICH- con la intención de formar a futuros dirigentes sindicales del país con un pensamiento social cristiano, inspirado en la Doctrina Social de la Iglesia Católica; allí no solo se entregaban los principios propios del sindicalismo sino que también los elementos que debían tener las empresas para que fueran justas con sus trabajadores; en el fondo, se estaban poniendo las bases de la Responsabilidad Social Empresarial.

A la luz de lo anterior, el objetivo de este trabajo es aportar la visión cristiana que ha tenido en Chile la Responsabilidad Social Empresarial.

Palabras clave: Responsabilidad Social Empresarial; Asociación Sindical Chilena; Unión Social de Empresarios Cristianos; Doctrina Social de la Iglesia; Pensamiento Social Cristiano.

ABSTRACT: Since the middle of the last century began coining the concept of Corporate Social Responsibility, which has gradually been specifying and introducing the new needs and problems of today's changing society.

However, in 1947, Father Alberto Hurtado founded Association Trade Union Chile -ASICH- with the intention of forming future trade union leaders in the country with a social thought Christian, inspired by the Social Doctrine of the Catholic Church; there not only were given the principles of trade unionism but that the elements that companies should have to be fair to its employees; in the background, they were laying the foundations of corporate social responsibility. 
In the light of the above, the objective of this work is to provide Christian view that has taken Corporate Social Responsibility in Chile.

Keywords: Corporate Social Responsibility; Chilean Trade Union Association; Social Union of Businessmen Christian; Social Doctrine of the Church; Christian Social thought.

SUMARIO: 1. Introducción. 2. El P. Hurtado y el contexto histórico chileno. 3. Pensamiento Social del P. Hurtado y la Doctrina Social de la Iglesia. 4. Formación de la Asociación Sindical Chilena -ASICH-. 5. Creación de la Unión Social de Empresarios Cristianos -USEC-. 6. La Responsabilidad Social Empresarial y la USEC. 7. Conclusiones. 8. Referencias bibliográficas.

\section{NTRODUCCIÓN}

En el siglo pasado se comenzó a utilizar en Estados Unidos y Europa el concepto de Responsabilidad Social Empresarial -RSE- para referirse al compromiso éticosocial que las empresas debían tener con sus trabajadores y con su entorno.

En Chile, sin embargo, en 1947 el P. Alberto Hurtado, s. j. (1901-1952) ${ }^{1}$ fundó la Asociación Sindical Chilena-ASICH-, a fin de preparar a los futuros dirigentes sindicales con un pensamiento social cristiano, basado en la Doctrina Social de la Iglesia Católica; allí, unido a la formación en los principios propios del sindicalismo, también se entregaban los elementos que debían tener las empresas para que fueran justas con sus trabajadores; es decir, se estaban asentando los principios de la responsabilidad social empresarial.

En esta actividad colaboraban estudiantes universitarios y académicos comprometidos con ese pensamiento, entre ellos, sobresalen William Thayer Arteaga y Eduardo Frei Montalva. En el contexto anterior, el 24 de mayo de 1948 se fundó, en presencia del P. Hurtado, la Unión Social de Empresarios Cristianos -USEC-; el 1 de enero de 1957 la USEC se integró a UNIAPAC (International Union of Christian Business Executives).

En el contexto anterior, el objetivo de este trabajo es aportar la visión cristiana que ha tenido en Chile la Responsabilidad Social Empresarial. Para ello, se presentará al P. Hurtado y el contexto histórico de Chile, desde su perspectiva, entre 1936 y 1952; el aporte de la Iglesia Católica a la justicia social en sus documentos que conforman su Doctrina Social presente en el pensamiento social del sacerdote jesuita en sus principales escritos; la fundación de la $\mathrm{ASICH}$ y la labor de la misma, para finalizar con la creación de la USEC, realizando una comparación con el desarrollo de la RSE a nivel internacional. En consecuencia, los resultados y conclusiones se ubican en señalar el aporte concreto que el pensamiento social cristiano ha realizado a la RSE en Chile.

${ }^{1}$ Es el segundo santo chileno, beatificado por S. S. Juan Pablo II el 16 de octubre de 1994 y canonizado por S. S. Benedicto XVI el 23 de octubre de 2005. 
La metodología utilizada es histórico-analítica; es decir, se utilizan las fuentes documentales del propio autor estudiado y la de otros contemporáneos; todo lo cual es analizado para efectuar el desarrollo con la argumentación necesaria para alcanzar el objetivo propuesto.

\section{EL P. HURTADO Y EL CONTEXTO HISTÓRICO CHILENO (1930-1952)}

El P. Hurtado nació como Luis Alberto en Viña del Mar -balneario distante a 120 $\mathrm{km}$ de la capital-, el 22 de enero de 1901. Era el primogénito de una familia aristocrática formada por Alberto Hurtado Larraín y Ana Cruchaga Tocornal.

Sus padres se habían establecido en el fundo Los Perales de Tapihue, al interior de Casablanca -distante 40 km de Viña del Mar-, y su situación económica estaba disminuida porque esas tierras no producían mucho y, por lo tanto, tenían fuertes deudas. En ese lugar, vivió sus primeros años el pequeño Luis Alberto hasta que en 1905 muere su padre en manos de bandoleros, quedando huérfano a los cuatro años, junto a su hermano Miguel de dos años. Su madre tuvo que vender el campo para pagar las deudas, y luego se trasladó a Santiago donde su hermano Jorge Cruchaga; allí vivirá 8 años hasta que muere el mismo; luego se trasladó a casa de su hermana Julia.

Esta situación de vivir como allegado y sentir en carne propia la pobreza, influirá significativamente en la vida personal y apostólica del joven Alberto.

Su madre, desde su infancia, comenzó a educarlo en los fundamentos del catolicismo. Por ello, buscó un colegio que transmitiera lo mismo que ella en el hogar: así Alberto ingresó al Colegio San Ignacio de Alonso Ovalle en 1909. A los diez años ya participaba en su Colegio en dos asociaciones religiosas: La Congregación Mariana y el Apostolado de la Oración. Tres años después, cursando el tercer Año de Humanidades, participó como Catequista del Colegio y desde los 16 años comenzó su labor social en los Patronatos ${ }^{2}$ : San Antonio, Andacollo, San José, Conferencia de San Vicente y, posteriormente (1920), participará en el Círculo de Estudios León XIII del P. Jorge Fernández Pradel, s. j., y como profesor del Instituto Nocturno San Ignacio para obreros, ubicado en Lord Cochrane N.161, cerca de su antiguo colegio.

En 1915, a la edad de 14 años, conoció al P. Fernando Vives Solar, s. j., quien fue su profesor de historia; él influirá significativamente en su formación espiritual y en su futuro como educador social y como sacerdote comprometido con el movimiento social-cristiano que se inició en Chile en la primera década del siglo. En una de sus principales obras Sindicalismo (1950) le dedicará su último libro al P.

${ }^{2}$ Eran lugares dependientes de parroquias $u$ organizaciones católicas en que acogían a los más necesitados, especialmente niños y jóvenes, y los ayudaban con educación cristiana y enseres materiales. 
Vives como «Apóstol de la redención proletaria, a quién debo mi sacerdocio y mi vocación social».

En ese mismo tiempo y, en forma paralela, se integró a la Asociación Nacional de Estudiantes Católicos -ANEC-, institución que había fundado en 1915 el Pbro. Julio Restat.

Tres años después, ingresó a la Universidad Católica de Chile a estudiar Derecho; a su vez, para poder colaborar con la mantención de su madre y su hermano menor, trabajaba en las tardes en una empresa periodística de un tío suyo. En la universidad fue un alumno excelente y se integró activamente-como ya se indicó-, en varias acciones religioso-sociales.

En sus estudios superiores centró su preocupación en lo social y en lo educacional en sus dos memorias y en su Tesis Doctoral. Fue así como, en 1921 realizó su memoria para optar al Grado de Bachiller en Leyes y Ciencias Sociales con el tema: Reglamentación del Trabajo de los Niños; a su vez, en 1923, investigó acerca de El Trabajo a Domicilio para optar al grado de Licenciado en la Facultad de Leyes y Ciencias Políticas, y por último, en 1935 analizó el sistema educacional de Dewey desde la perspectiva católica en su Tesis Doctoral en Lovaina.

Finalmente, pudo resolver la situación económica de su familia, se recibió de abogado e inmediatamente, el 14 de agosto de 1923, inició su viaje al Noviciado de Chillán. Esa fecha no fue al azar: la escogió para llegar el día de la Asunción de María, mismo día en que San Ignacio había hecho sus votos. Allí fue nombrado bedel ${ }^{3}$ del grupo, considerando su profesión; también organizó un centro catequístico.

Dos años después, el 13 de abril, se trasladó en tren a Córdova -Argentina- atravesando la cordillera de los Andes, ciudad en la cual finalizó su Noviciado y realizó su juniorado el 15 de agosto de 1925. Dos años después partió a Barcelona -España-, en donde estudiará tres años de Filosofía en el Colegio Sarriá de esa importante ciudad catalana y el primer año de Teología. En ese lugar, estaba su antiguo amigo, el P. Fernando Vives, pues había sido expulsado de Chile por sus ideas sociales de avanzada. En 1931, debido a la guerra civil española, se trasladó a Irlanda por cinco meses. En septiembre del mismo año, fue enviado a Bélgica para terminar sus estudios teológicos. En Lovaina, estudió paralelamente Pedagogía doctorándose el 10 de octubre de 1935. Dos años antes, había sido ordenado sacerdote por el Cardenal Van Roey, Primado de Bélgica.

Después de su defensa de su tesis doctoral, recorrió por Alemania, Austria, Italia y Francia, visitando colegios y reuniendo libros para una exposición de obras de Pedagogía, solicitadas por el Rector de la Universidad Católica de Chile -Monseñor Carlos Casanueva-, quien también había sido su confesor. También visualizó el funcionamiento de las empresas y las relaciones entre empleadores y trabajadores, percibiendo que en algunas de ellas se practicaba la justicia social y en otras no.

\footnotetext{
${ }^{3}$ Encargado de la disciplina; ayudante del Rector del Seminario.
} 
En enero del año siguiente, atravesó el océano atlántico hacia Buenos Aires; en tren se encaminó a Chile. Mons. Casanueva, lo aguardaba con una jornada completa en la Universidad Católica como profesor de pedagogía en la Facultad de Filosofía y Letras con el objeto de fundar pronto la Escuela de Pedagogía, dependiente de esa Facultad. No obstante, el Provincial de su orden lo destinó como profesor de religión en el colegio en el cual él mismo había estudiado; por lo tanto, solo pudo ir a la universidad una o dos tardes por semana a dictar Conferencias, especialmente de Psicología Pedagógica y del Desarrollo del Adolescente. De esta manera, comenzó su corta, pero fructífera y extensa labor sacerdotal, centrando su acción en el rol de educador social, inspirado en la Doctrina Social de la Iglesia Católica. Como se verá más adelante, asesoró a la Acción Católica entre 1941 y 1944; fundó el Hogar de Cristo para acoger a la gente de calle -niños, jóvenes y adultos- en 1944; creó la ASICH en 1947 y la USEC al año siguiente; finalmente en 1951 -once meses antes de dejar este mundo- fundó la revista Mensaje; este es un medio periodístico que aún existe para analizar y debatir, a la luz del evangelio, los principales problemas nacionales e internacionales, tratando de encontrar respuesta y proponer soluciones frente a la realidad compleja existente; está dirigido especialmente para la elite intelectual. Esta revista persigue que los católicos, al igual que la Compañía de Jesús, estén a la vanguardia en los cambios que los tiempos exigen sin descuidar la inspiración cristiana (Caiceo, 1988).

Cuando Alberto Hurtado regresa a Chile desde Europa en 1936 -en donde había desarrollado su doctorado en Pedagogía en Lovaina-, realizando un aporte significativo con su tesis --defendida en 1935 (Hurtado, 1994), al lograr conciliar 14 principios pedagógicos del educador norteamericano John Dewey con el pensamiento católico (Caiceo, 2016)-, se encuentra con un país diferente al que él había dejado 10 años antes.

Para describir la situación social y religiosa del país, utilizando el método científico, consulta, a través de encuestas, a las diferentes parroquias, concluyendo que en el país existía una verdadera lacra social y con una escasísima práctica litúrgica y vivencial del cristianismo y, por lo tanto, Chile no era un país católico (Hurtado, 1941). Pero lo más grave, a su juicio, era que los responsables de la sociedad chilena, los dirigentes que se decían católicos, no practicaban la Doctrina Social de la Iglesia. Respecto a la situación social crítica existente señaló en otra de sus obras que la deficiente educación era una de sus causas:

Los dolores chilenos tienen una honda raíz educativa. Pobre es nuestro pueblo, pero su misma ignorancia es la raíz más profunda de su pobreza... Antes que nada hay que pedir al gobierno que abandone su politiquería para ir de frente al fondo del problema nacional que exige ante todo levantar el nivel cultural con la colaboración de todos los hombres de buena voluntad (Hurtado, 1947, p. 68). 
Uno de los principios que rescata de Dewey ${ }^{4}$ para la pedagogía católica es el que resume como que la escuela es un instrumento de reforma social, indispensable para que en una sociedad se realicen los cambios estructurales necesarios para que exista justicia social. Toda la vida sacerdotal y acción del P. Hurtado se encaminan en ese sentido, especialmente en tratar de cambiarle la mentalidad a la élite joven chilena porque ella cuando tuviera en sus manos el poder podría tomar las decisiones necesarias para efectuar los cambios esperados de acuerdo a la Doctrina Social de la Iglesia y poder decir, efectivamente, Chile es un país católico.

Hoy día, se escucha que la única forma de eliminar la pobreza es entregando mayor educación; hace 78 años el P. Hurtado ya lo estaba pregonando.

Como él deseaba que el país efectivamente fuera católico, propuso iniciar la transformación de la élite intelectual católica chilena. Por ello inició retiros a jóvenes y adultos con el objeto de inculcarles una profunda espiritualidad, en que conocieran el evangelio y fueran capaces de entender exactamente la palabra de Dios; a los primeros, a su vez, los motivó para el sacerdocio, convirtiéndose en uno de los mayores captadores de candidatos al sacerdocio y a la vida religiosa en Chile. Se interesó especialmente por los jóvenes porque a través de la Acción Católica intentaba alcanzar el cambio de mentalidad social cristiana en ellos para que después efectuaran como adultos los cambios sociales necesarios para alcanzar la justicia social. Por ello fue el Asesor Nacional de la Acción Católica entre 1941 y 1944, entregando su mensaje de fe y compromiso social a los jóvenes de todo el país.

El P. Hurtado murió de cáncer al páncreas en la Clínica de la Universidad Católica, el 18 de agosto de 1952.

Por último, hay que indicar que en 1977 se introdujo la causa de Beatificación y Canonización de P. Alberto Hurtado por Decreto el Sr. Arzobispo de Santiago, Cardenal Raúl Silva Henríquez; después del proceso correspondiente, el 16 de octubre de 1994 fue beatificado por San Juan Pablo II, y el 23 de octubre del 2005 S. S. Benedicto XVI lo canonizó, pasando a ser el segundo santo chileno ${ }^{5}$.

${ }^{4}$ John Dewey es uno de los principales exponentes de la Escuela Nueva. El pensamiento pedagógico de este educador norteamericano influyó en las principales reformas del siglo xx en Chile (Ley de Instrucción Primaria Obligatoria de 1920, Reforma de 1927 para la Educación Primaria, Reforma de 1945 para la Educación Secundaria, Reforma de 1965 para todo el sistema escolar) (Caiceo, 2016) y el sacerdote jesuita "cristianizó» a este educador, descubriendo 14 principios pedagógicos suyos conciliables con el catolicismo (Hurtado, 1994).

${ }^{5}$ El 21 de marzo de 1993, Santa Teresa de Los Andes se había convertido en la primera santa chilena. 


\section{PENSAMIENTO SOCIAL DEL P. HURTADO Y LA DOCTRINA SOCIAL DE LA IGLESIA}

En el pensamiento del sacerdote jesuita están mezclados lo educacional y lo social; a su juicio, es necesario educar en la doctrina social-cristiana para provocar los cambios sociales necesarios. Sus fuentes de inspiración se encuentran en la filosofía neo-tomista ${ }^{6}$, las Encíclicas Sociales, Rerum Novarum (León XIII, 1891), Quadragessimo Anno (Pío XI, 1931), la Encíclica Educacional Divini Illius Magistri (Pío XI, 1929) y en el pensamiento de la Escuela Nueva en la persona de Dewey, específicamente.

Respecto a la educación social, el P. Hurtado desea proseguir el trabajo de su maestro, el P. Fernando Vives, s. j. en el campo social: Hacer tomar conciencia a los cristianos de las injusticias de su tiempo y del deber de impulsar los cambios sociales necesarios para transformar a la sociedad chilena en una sociedad más acorde con el evangelio y la doctrina social presente en las encíclicas sociales de su época. Para alcanzar adecuadamente una educación social es imprescindible darles a los educandos una formación del sentido social, entendiendo por ello

...aquella cualidad que nos mueve a interesarnos por los demás, a ayudarlos en sus necesidades, a cuidar de los intereses comunes. Si ensayamos una definición más cabal, podemos decir que es aquella aptitud para percibir y ejecutar prontamente, como por instinto, en las situaciones concretas en que nos encontramos, aquello que sirve mejor al bien común (Hurtado, 1947, p. 170).

De tal forma que, a su juicio, la educación social se expresa de diferentes maneras (Caiceo, 1989):

- Valorando la justicia en sus reales dimensiones, sin confundirla con la benevolencia o la caridad.

- Inculcando la caridad, como amor al prójimo.

- Formando para la transformación de la realidad a partir del conocimiento de los problemas existentes en la sociedad.

- Practicando la justicia, la caridad y la solución de problemas en el trato social de cada día. Parafraseando a Dewey, dirá: «La educación prepara para la vida por la práctica de la misma vida» (Hurtado, 1947, p. 239).

${ }^{6}$ El sacerdote jesuita se formó en la filosofía del Doctor Angélico, pero también asumió los planteamientos de Jacques Maritain, especialmente lo planteado en el Humanismo Integral (1966); la publicación original en francés se publicó en 1936, reeditándose posteriormente); por lo mismo, una de las obras fundamentales de este sacerdote se llama Humanismo Social (1947). Estuvo bastante ligado a la filosofía política del filósofo francés, especialmente en la formación de jóvenes (Caiceo, 1994). 
- Enseñanza de valores humanos, tales como la solidaridad, la dignidad del trabajo, la generosidad, la fraternidad, la responsabilidad, la dignidad de todo hombre, la libertad, la verdad, la sobriedad, la rectitud, el espíritu de sacrificio, el fortalecimiento del carácter y de la voluntad y la castidad (Hurtado, 1947, pp. 291, $147,270,288,179,127,180,181,199,139,149,317,268)$.

- Formando para una recta acción política que promueva la paz y la democracia, y para una adecuada acción cívica, económico-social e intelectual, que signifique compromiso con el país, la comuna, la organización social y la creación y difusión de un pensamiento renovador por parte de los futuros ciudadanos (Hurtado, 1947: pp. 279-286). Sobre esto es destacable la siguiente frase: «Las revoluciones más que con fusiles se combaten con una justa renovación» (Hurtado, 1947, p. 281).

\section{FORMACIÓN DE LA ASOCIACIÓN SINDICAL CHILENA -ASICH-}

Una de las principales acciones de Alberto Hurtado como educador social fue la formación de la Asociación Sindical Chilena -ASICH- con el objeto de formar sindicalistas cristianos y empresarios imbuidos de la Doctrina Social de la Iglesia.

Un importante sacerdote jesuita, señala al respecto:

Para poner una fecha, pongamos 1946, cuando el P. Hurtado ya tenía 10 años de trabajo apostólico en Chile, había sido director de la Juventud de Acción Católica y, movido por la pobreza social, había fundado el Hogar de Cristo. Entonces parece haber captado más plenamente la necesidad de una presencia de la Iglesia y su mensaje social en el mundo obrero del país (Aldunate, 2005, p. 32).

El principal sindicalista cristiano chileno del siglo pasado le ayudó estrechamente en esta acción: don Clotario Blest ${ }^{7}$. Para formalizar la fundación de esta Institución y evitar que fuera acusado nuevamente de proselitismo político de izquierda -como lo fue cuando era Asesor Nacional de la Acción Católica- se dirigió a Roma a solicitarle al Papa Pío XII la autorización para crear la ASICH (1947), a través de un Memorandum de 30 párrafos -entregado personalmente al Papa el 18 de octubre de 1947- en los cuales describe la situación social ${ }^{8}$,

${ }^{7}$ Principal impulsor de la creación de la Asociación Nacional de Empleados Públicos -ANEF-, concretada el 5 de mayo de 1943, convirtiéndose en su primer Presidente y, a su vez, también lideró la fundación de la Central Única de Trabajadores -CUT- en 1953, transformándose igualmente en su primer Presidente.

${ }^{8}$ Relata entre otros aspectos: la diversidad de condiciones económicas y sociales; situación laboral en el campo y control marxista de los obreros en las ciudades; muchos católicos no practicaban la justicia social (Thayer, 2004). 
religiosa ${ }^{9}$ y política ${ }^{10}$ del país, solicitándole "una gracia especialísima»: crear un organismo para preparar dirigentes obreros, con los métodos de la Asociación Católica de Trabajadores Italianos -ACLI- y a preparar a futuros "patrones» jóvenes en la doctrina social de la Iglesia (Thayer, 2004). A los pocos días, el 10 de noviembre del mismo año, Monseñor Tardini, Secretario de Estado del Vaticano, le respondía que el Sumo Pontífice había tenido -con el informe escrito que él le había entregado sobre la realidad chilena-, una confirmación de la grave situación religiosa, moral y social de Chile y, por lo mismo, deseaba alentarlo calurosamente al propósito que le había expuesto en el sentido de ayudar al generoso grupo de seglares católicos que se proponía desarrollar un vasto plan de trabajo social según los principios de la doctrina católica, bajo la dependencia de la jerarquía eclesiástica y con plena sumisión a ella, apartado completamente de la política de partidos.

La propuesta realizada al Papa Pío XII constituye un plan social de seis puntos:

1. Formación de dirigentes obreros;

2. Formación de jóvenes patrones ${ }^{11}$;

3. Hacer investigaciones serias de la realidad, como medio de formación;

4. Propagar estas ideas;

5. Buscar el mejoramiento de la suerte de los trabajadores;

6. Actuar con sumisión a la Jerarquía y fuera de la política de partidos (Thayer, 2004: p. 128).

La ASICH, sin embargo, se había fundado antes de la autorización Papal, el 13 de junio de 1947 y se había congelado mientras no llegara la autorización mencionada. El texto del Acta de Fundación, suscrita por el sacerdote jesuita y 13 laicos intelectuales, señala:

Con esta fecha, 13 de junio de 1947, día del Sagrado Corazón, con asistencia de los firmantes, se constituyó la Acción Sindical Chilena que pretende hacer realidad en Chile la redención del proletariado de acuerdo con las normas de las encíclicas sociales de la Iglesia (Thayer, 2004, p. 24).

\footnotetext{
${ }^{9}$ Después de la separación Iglesia-Estado a partir de 1925, el país se fue laicizando; había escasez de sacerdotes y disminución de la práctica religiosa (Thayer, 2004); todo ello lo había evidenciado en su investigación, ya mencionada, publicada en 1941 con el título ¿Es Chile un País Católico?

${ }^{10}$ Se centra en las relaciones Iglesia-Partido Conservador; el nacimiento de la Falange al interior del mismo Partido y su posterior separación; intento por parte de los conservadores de que la Iglesia condene al nuevo partido, situación superada con la Carta del Cardenal Pacelli en 1934 (Thayer, 2004).

${ }^{11}$ El Código del Trabajo de 1931 le daba ese nombre a los empleadores de los obreros.
} 
Cuando el P. Hurtado regresó a Chile, el Provincial de la Compañía, P. Álvaro Lavín ${ }^{12}$, no tuvo más que ratificarle la fundación de la $\mathrm{ASICH}$.

La ASICH desde un comienzo se instauró como un movimiento por los trabajadores y para los trabajadores (ya sean de la ciudad o del campo), pretendió desplazar el capitalismo liberal y promover la instauración de un Orden Social Cristiano en el país. Por tal motivo, se presentó también como un punto de inflexión entre la hegemonía política de los sindicatos, puesto que su estructura no correspondía a la de un sindicato, sino más bien a un para-sindicato o Escuela Sindical (Ramírez, 2013, p. 82).

La organización se extendió a todo el país en 1949, contando con tres secciones: obreros, empleados e intelectuales. Pronto se organizó un Departamento Económico-Social y una Escuela Sindical. Como aporte a esta actividad el P. Hurtado publicó una obra muy erudita con datos precisos de todo el mundo hasta mediados del siglo pasado acerca del Sindicalismo (Hurtado, 1950). A comienzos de 1949, el sacerdote jesuita le informa a su Provincial la marcha de la institución, precisando algunos aspectos claves:

Objetivos y tácticas: Despertar en los obreros cristianos la conciencia de sindicarse y agrupar a los cristianos ya sindicados para que con plena formación luchen en el interior de los sindicatos por la implantación del orden social cristiano. Por tanto, no sindicatos aparte, sino acción en el seno de los sindicatos organizados para influir al máximo en ellos por la presencia en su interior de hombres que levanten la masa como la levadura.

La acción de la ASICH es totalmente ajena a toda política, y combate toda acción política en el seno de los sindicatos para que no los desvirtúe de su carácter estrictamente gremial (Hurtado en Thayer, 2004, pp. 59-60).

Según el sacerdote jesuita mencionado anteriormente «... la manera como quiso realizar su proyecto fue realista y acertada. Partió de los principios de la Acción Católica (acción de laicos, de los mismos trabajadores cristianos con el método verjuzgar-actuar), adaptados a la realidad chilena» (Aldunate, 2005: p. 35).

Con esta actividad pensaba echar las bases de los cambios sociales desde una perspectiva católica en el frente mismo de batalla: las organizaciones laborales. Desgraciadamente, por divisiones internas y, a pesar del empeño por mantenerla por parte del Capellán, sucesor del fundador, P. Jaime Larraín, s. j., la institución se disolvió en 1955 (Ramírez, 2013).

${ }^{12}$ Posteriormente será el primer Postulador de la Causa de Canonización del P. Alberto Hurtado Cruchaga. 


\section{CREACIÓN DE LA UNIÓN SOCIAL DE EMPRESARIOS CRISTIANOS -USEC-}

A mediados de 1948, en el local de la ASICH en la calle Alonso Ovalle en Santiago, se produjo una reunión en la cual estaban, entre otros, el P. Hurtado, junto al sacerdote mercedario Ramón Coo, William Thayer y los empresarios Jorge Matetic y José Luis Claro; se conversa sobre las buenas relaciones que debería haber entre la $\mathrm{ASICH}$ y los grupos patronales, concluyendo que es mejor fundar una organización centrada en la acción de los empleadores, la cual pasaría a llamarse Unión Social de Empresarios Cristianos -USEC-. De esta forma, el 30 de agosto de 1948 se concreta la primera reunión formal de la nueva entidad, a la cual asisten «D. Jorge Matetic; D. Patricio Bañados; D. José Luis Claro; D. Eduardo Arteaga; D. Juan Abogabir y D. Manuel Ossa U. Asistió también nuestro Asesor, R. P. R. Coo» (Thayer, 2004: p. 140). Rápidamente, durante el resto del mismo año se integraron más de 66 personas. Inicialmente se funda con el nombre de Unión Social de Industriales Católicos -USIC-; el 6 de diciembre de 1948 se cambia a Unión Social de Empresarios Católicos -USEC-; con el tiempo se cambió católicos por cristianos, manteniendo la misma sigla.

En sesión del 27 de septiembre de 1948 se acuerda invitar más empresarios a participar y se adjunta una carta explicativa con los principales fines de la institución:

1. Estudio y difusión de la doctrina social de la Iglesia Católica.

2. Cooperar al incremento y prosperidad de las Industrias de Chile, en beneficio general de los que trabajan en ellas, sin distinción de credos políticos o religiosos y fomentar por todos los medios posibles la unión y la cooperación entre capital y trabajo, llevándolos al convencimiento de que el interés de unos y otros está ligado al éxito de la explotación industrial.

3. Impulsar la realización de toda obra social que tienda a elevar material y espiritualmente a nuestras clases trabajadoras.

4. Facilitar el cumplimiento de los deberes religiosos, familiares y cívicos de las mismas.

5. Defender los legítimos intereses de todos los que trabajan en la industria, sean patrones, empleados u obreros, de toda intervención que altere los principios de justicia, orden, trabajo y armonía que deben existir dentro del mundo del trabajo.

6. Cooperar al mejoramiento y aumento de las construcciones para empleados y obreros.

7. Impulsar la formación de escuelas para empleados y obreros y para los hijos de éstos.

8. Impulsar obras de asistencia social que tiendan a mejorar las condiciones de vida familiar de los trabajadores industriales.

9. Impulsar y propiciar la formación de cooperativas de crédito, de consumo o de habitaciones de empleados y obreros. 
10. Impulsar todas aquellas obras que ocupen las horas libres para empleados, obreros y sus familias, como vacaciones, deportes, representación de obras teatrales, competencias, fiestas, etc. (Thayer, 2004, pp. 143-144).

El año recién pasado (2018) se cumplieron, por lo tanto, 70 años de la fundación de USEC por iniciativa del P. Hurtado.

\section{LA RESPONSABILIDAD SOCIAL EMPRESARIAL Y LA USEC}

La Responsabilidad Social Empresarial -RSE- comienza a gestarse a fines del siglo XIX y comienzos del XX, cuando tanto en los países como en la Iglesia Católica, acuñaron el concepto de trabajador

... como sujeto de derechos: derecho a un trabajo, a un salario y a un trato justo. Los Estados, a través de la legislación laboral impusieron normas protectoras; y la Iglesia Católica, a través de su Doctrina Social promovió una conciencia ética entre los empresarios (Balterra, Díaz, 2005, p. 20).

Sin embargo, se comienza explícitamente a hablar de RSE en el mundo académico y de los negocios, cuando Howard Bowen publicó en 1953 su libro Responsabilidad Social del Empresario, el cual tuvo profundas repercusiones, pues este autor, considerado el pionero o el padre de la RSE, señala que es obligación del empresario tomar decisiones en favor de los objetivos y valores de la sociedad (Carroll, 1999).

Es necesario, a su vez, consignar que Vives (2014) subraya que la RSE ha surgido en los países desarrollados, basada en las experiencias, información e investigaciones de las grandes empresas de esos países; por lo cual no es fácil que se adapte a los ecosistemas de los países en vías de desarrollo.

No existe, sin embargo, un concepto unívoco de RSE (Aravena, 2018), a pesar de las investigaciones diversas que se han realizado; empero, se ha continuado avanzando en el desarrollo del término.

En los últimos 65 años, en la medida que se ha establecido la globalización y el libre mercado se ha establecido con fuerza la competitividad; empero, se ha ido tomando conciencia que

... un elemento nuevo de competitividad estaría en la capacidad de las empresas para incorporarse a los mercados y permanecer en ellos, lo cual depende no sólo de su tecnología, de sus procesos productivos y de su gestión financiera, sino que también de su comportamiento en materia de respeto y cuidado del medio ambiente, de la comunidad y de sus trabajadores, como personas con intereses, motivaciones, capacidades, necesidades de desarrollo y sujetos de derechos: individuales y colectivos (Balterra, Díaz, 2005, p. 17). 
Por lo mismo, en décadas recientes se ha insistido que la RSE es el concepto que relaciona en forma teórica y práctica a las empresas con la sociedad (Werther $\&$ Chandler, 2011); en esta década, reforzando esa idea existen varios autores que definen la Responsabilidad Social Empresarial como la relación entre la empresa y la sociedad (Bocean et al., 2014; D’Aprile \& Mannarini, 2012).

En el sentido anteriormente expuesto, se entiende que

La empresa, como organización que entrega bienes y servicios a la sociedad, creando riquezas para sus dueños, tiene un rol cada vez más relevante en los problemas ambientales, sociales y económicos. Es así, como distintas corrientes del pensamiento ven a la empresa no sólo cómo proveedor de bienes y servicios, sino que también, como un actor que debe reflexionar acerca de cómo genera esos bienes y servicios, y las consecuencias para la sociedad, de ese actuar (Aravena, 2018, p. 10).

En ese contexto, se ha hecho tan importante el cuidado del medio ambiente por el cambio climático al cual está expuesto el planeta tierra que, incluso el actual Papa Francisco, ha publicado con mucha fuerza su encíclica Laudato si (2015), señalando que es necesario cuidar nuestra casa común; recuerda, a su vez, que ya en 1971 Paulo VI había señalado que "debido a una explotación inconsiderada de la naturaleza, el ser humano corre el riesgo de destruirla y de ser a su vez víctima de esta degradación» (Francisco, 2015, N. ${ }^{\circ}$ 4). Agrega que Juan Pablo II «llamó a una conversión ecológica global» (Francisco, 2015, N. ${ }^{\circ} 5$ ) y que su antecesor, Benedicto $\mathrm{XVI}$, indicó que es necesario "eliminar las causas estructurales de las disfunciones de la economía mundial y corregir los modelos de crecimiento que parecen incapaces de garantizar el respeto del medio ambiente» (Francisco, 2015, N. ${ }^{\circ} 6$ ). Por lo mismo, siguiendo lo que San Francisco de Asís señalaba hace 800 años respecto al cuidado de la naturaleza, él se refiere en su encíclica a la contaminación, la basura, la cultura del descarte, el clima como bien común, el problema del agua, la pérdida de la biodiversidad, todo lo cual está significando un deterioro de la calidad de la vida humana y degradación social y, a su vez, está poniendo en peligro la subsistencia de toda vida en el planeta.

De esta forma, se mantienen los mismos actores del origen de la RSE, los estados -salvo los planteamientos de Trump en Estados Unidos- y la Iglesia Católica.

Es necesario precisar que la RSE presenta en las investigaciones y literatura, diversas perspectivas: ambiental, social y económico. Carroll (1979), por su parte, señala que son: económicas, legales, éticas y filantrópicas.

Por su parte, la USEC se ha mantenido hasta el presente, conmemorando el año pasado (2018) su septuagésimo aniversario, con los ideales iniciales, adecuándose, por cierto, a los requerimientos de la sociedad del conocimiento. La propia organización señala respecto a su historia: 
En sus 70 años de vida, la gran red de empresarios, ejecutivos y emprendedores que conforman USEC, ha logrado unirse en pos de alcanzar el ideal de construir una sociedad más humana, justa, libre y solidaria. Esto a través del aporte al pleno desarrollo humano de los hombres y mujeres de empresa, visto desde la perspectiva que nos enseña la Doctrina Social de la Iglesia y sus principios (Historia USEC, 2018).

En los objetivos actuales de la institución se percibe la adecuación a los desafíos de hoy, introduciendo el concepto de emprendedores, pero manteniendo el origen de la institución, fomentando el desarrollo personal y el de los trabajadores con un profundo humanismo. Textualmente se indica:

En USEC buscamos aportar al desarrollo de la sociedad motivando a empresarios, ejecutivos y emprendedores para que respondiendo al llamado a vivir su actividad empresarial como una noble vocación, se comprometan a su mejoramiento personal, el de sus organizaciones y el medio empresarial, esta es la base de nuestra misión que nos inspira a humanizar la sociedad desde el mundo del trabajo (Ven y Súmate, 2018).

Actualmente la USEC funciona con un gobierno corporativo formado por los directores de la institución, empresarios y ejecutivos, representantes del mundo académico y de los centros de estudio, asesores pastorales y socios en general. Su actual Presidente es Ignacio Arteaga. Sus asesores doctrinales son Mons. Fernando Chomalí, Arzobispo de Concepción, el Pbro. Samuel Fernández y el P. Fernando Montes, s. j.

Al hacer una comparación entre la RSE y LA USEC se puede apreciar que los planteamientos de la RSE están insertos en la USEC -incluso fueron planteados 5 años antes que se hablara explícitamente en el mundo académico de RSE- y que esta trata de mantenerse fiel a los objetivos iniciales trazados por su fundador, el P. Alberto Hurtado.

\section{CONCLUSIONES}

Al llegar al final de este artículo se puede constatar que, en sus orígenes a nivel mundial, la RSE surgió tanto por influencia de los estados como de la Iglesia Católica. En el caso de Chile, primero estuvo presente en las inquietudes sociales del P. Hurtado -inspirado en la doctrina católica-, quién creó la ASICH (1947) y luego, a partir de ella, la USEC (1948); en el mundo académico, en cambio, a nivel internacional, solo se comenzó a hablar de RSE a partir de 1953; en Chile fue entrando más lentamente a partir de fines de la década del 50. Por lo tanto, se puede concluir que, en este país, inicialmente la RSE estuvo fundamentada en la visión cristiana aportada por San Alberto Hurtado. 
Es importante, a su vez, constatar la importancia que el sacerdote jesuita le dio al sindicalismo, formando a los trabajadores para defender sus derechos con justicia y equidad y también a los empresarios para que respetaran y practicaran la Doctrina Social de la Iglesia. De esta forma, si los representantes del trabajo y del capital marchan juntos, todos se benefician, incluido el país en su conjunto.

La última encíclica Laudato si (2015) del actual Pontífice revela que la Iglesia desea seguir liderando los planteamientos de la RSE al señalar explícitamente la necesidad de cuidar en el desarrollo económico y tecnológico, la que él denomina la casa común, es decir, nuestro planeta y con ello, nuestra propia existencia.

Finalmente, es imprescindible constatar que no habrá futuro promisorio para Chile y el mundo, si no se desarrollan a cabalidad los principios de la Responsabilidad Social Empresarial, la cual se ha ido extendiendo hacia diversos aspectos para responder a las nuevas necesidades de la sociedad actual.

\section{REFERENCIAS BIBLIOGRÁFICAS}

Aldunate, J. (2005). El Proyecto Social del Padre Hurtado. Revista Mensaje, junio, 32-35.

Aravena, L. (2018). Construcción de un Modelo de Responsabilidad SocialEmpresarial, desde la Perspectiva de los Significados para los Empresarios/as y las Prácticas de las Empresas en Chile. Tesis para optar al Grado de Doctor en Ciencias de la Administración. Santiago de Chile: Universidad de Santiago de Chile.

Balterra, P. y Díaz, E. (2005). Responsabilidad Social Empresarial: Alcances y Potencialidades en Materia Laboral. Santiago de Chile: Gobierno de Chile, Dirección del Trabajo, Departamento de Estudios, Cuaderno n. ${ }^{\circ} 25$.

Bocean, C., Delattre, M., Ocler, R. y Sitnikov, C. (2014). Towards a critical study of standardization. Society and Business Review, 9(3), pp. 298-309.

Caiceo, J. (1988). Cap. III, E: «Alberto Hurtado Cruchaga, s.j. (1901-1952)». En L. Celis, J. Caiceo, E. Sánchez, S. López y F. Aliaga, Universidad Católica de Chile: Hombres e Ideas (1900-1950) (pp. 245-273). Santiago de Chile: Ediciones Pontificia Universidad Católica de Chile.

Caiceo, J. (1989). El Ideario Educativo del Padre Alberto Hurtado. La Revista Católica, 1.084, pp. 339-350. 
Caiceo, J. (1994). Maritain, la Política y el Social Cristianismo en Chile. Santiago de Chile: Ediciones Facultad de Filosofía, Pontificia Universidad Católica de Chile.

Caiceo, J. (2016). La Pedagogía de Dewey en Chile: Su Presencia, a través de sus Discípulos, durante el Siglo XX. Santiago de Chile: Ediciones de Departamento de Contabilidad y Auditoría y Departamento de Educación de la Universidad de Santiago de Chile.

Carroll, A. B. (1979). A Three-Dimensional Conceptual Model of Corporate Performance. The Academy of Management Review, 4(4), pp. 497-505.

Carroll, A. B. (1999). Corporate Social Responsibility. Evolution of a Definitional Construct. Business \& Society, 38(3), pp. 268-295.

D’Aprile, G. y Mannarini, T. (2012). Corporate Social Responsibility: A Psychosocial Multidimensional Construct. Journal of Global Responsibility, 3(1), pp. 48-65.

Francisco, Papa. (2015). Laudato si. Santiago de Chile: Ediciones Paulinas.

Historia USEC. (2018). Consultada el 30 de abril de 2018 en <http://www.usec.cl/ quienes-somos/historia>.

Hurtado, A. (1921). Reglamentación del Trabajo de los Niños. Tesis para optar al Grado de Bachiller en Leyes y Ciencias Sociales. Santiago de Chile: Universidad Católica de Chile.

Hurtado, A. (1923). El Trabajo a Domicilio. Tesis para optar al Grado de Licenciado en Leyes y Ciencias Políticas. Santiago de Chile: Universidad Católica de Chile.

Hurtado, A. (1941). ¿Es Chile un País Católico? Santiago de Chile: Editorial Splendor.

Hurtado, A. (1947). Humanismo Social. Ensayo de Pedagogía Social. Santiago de Chile: Editorial Difusión.

Hurtado, A. (1950). Sindicalismo. Historia, Teoría, Práctica. Santiago de Chile: Editorial del Pacífico.

Hurtado, A. (1994). El Sistema Pedagógico de John Dewey ante las Exigencias de la Doctrina Católica. Traductor: Caiceo, J. Santiago de Chile: Ediciones Universidad Católica Blas Cañas, 2a. ed. 
León XIII. (1966). Rerum Novarum. Santiago de Chile: Ediciones Paulinas. Versión original de 1891.

Maritain, J. (1966). Humanismo Integral. Problemas Temporales y Espirituales de una Nueva Cristiandad. Buenos Aires: Ediciones Carlos Lohlé.

Pío XI. (1966). Divini Illius Magistri. Santiago de Chile: Ediciones Paulinas. [Versión original de 1929].

Pío XI. (1967). Quadragessimo Anno. Santiago de Chile: Ediciones Paulinas. [Versión original de 1931].

Ramírez, T. (2013). La Acción Sindical Económica y Chilena Asich: Una Alternativa para la Libertad Sindical en Chile: 1947-1955. Santiago de Chile: Universidad Alberto Hurtado.

Thayer, W. (2004). Ni Político ni Comunista. Sacerdote, Sabio y Santo. Santiago de Chile: Olmué Ediciones Ltda.

Ven y Súmate. (2018). Consultada el 30 de abril de 2018 en <http://www.usec.cl/>.

Vives, A. (2014). Guías para la Responsabilidad Social en las PyMEs: Efectividad de Herramientas de Autoevaluación. Revista De Globalización, Competitividad y Gobernabilidad, 8(2), pp. 29-54.

Werther, B. y Chandler, D. (2011). Strategic Corporate Social Responsibility: Stakeholders in Global environment. 2nd ed. 413 p. London: Sage Publication. 